\title{
Optimization of alcoholic fermentation of custard apple juice by Saccharomyces cerevisiae using response surface methodology
}

\section{Huan T. Phan*, \& Hien M. Nguyen}

Faculty of Food Science and Technology, Nong Lam University, Ho Chi Minh City, Vietnam

\section{ARTICLE INFO} \\ Research Paper \\ Received: March 30, 2019 \\ Revised: August 15, 2019 \\ Accepted: September 03, 2019 \\ Keywords \\ Custard apple juice \\ Fermentation \\ Response surface methodology \\ Saccharomyces cerevisiae

\section{*Corresponding author} \\ Phan Tai Huan \\ Email: pthuan@hcmuaf.edu.vn
}

\begin{abstract}
In recent years, custard apple fruit has been applied in food processing with various products. The objective of this study was to valorize a fermented fruit drink from a Vietnamese local custard apple fruit by the alcoholic fermentation of the juice using Saccharomyces cerevisiae. Response surface methodology was used to describe dependency of soluble solid content, inoculum size of yeast and fermentation time on ethanol production during fermentation of custard apple juice by Saccharomyces cerevisiae SLS. The experiments were performed according to the central composite design with total soluble solid content ranging from 16 to $20^{\circ}$ Brix, inoculum size of yeast from $1 \%$ to $3 \%$, and fermentation time from 42 to $48 \mathrm{~h}$. A quadratic model was developed to correlate the variables to the ethanol yield and sensory score. The results showed that a production of ethanol from the custard apple juice could be achieved reaching up to $5.1 \%(\mathrm{v} / \mathrm{v})$ at optimum conditions of $19^{\circ}$ Brix, $2 \%$ yeast and 44 -h fermentation time. The model predictions agreed satisfactorily with the experimental values.
\end{abstract}

Cited as: Phan, H. T., \& Nguyen, H. M.. (2019). Optimization of alcoholic fermentation of custard apple juice by Saccharomyces cerevisiae using response surface methodology. The Journal of Agriculture and Development 18(5), 70-78. 


\title{
Tối ưu hoá quá trình lên men rượu dịch quả mãng cầu ta bằng Saccharomyces cerevisiae sử dụng phương pháp bề mặt đáp ứng
}

\author{
Phan Tại Huân* \& Nguyễn Minh Hiền \\ Khoa Công Nghệ Thực Phẩm, Trường Đại Học Nông Lâm TP.HCM, TP. Hồ Chí Minh
}

\author{
THÔNG TIN BÀI BÁO \\ Bài báo khoa học \\ Ngày nhận: 30/03/2019 \\ Ngày chỉnh sửa: 15/08/2019 \\ Ngày chấp nhận: 03/09/2019 \\ Từ khóa \\ Dịch quả mãng cầu ta \\ Lên men \\ Phương pháp bề mặt đáp ứng \\ Saccharomyces cerevisiae \\ *Tác giả liên hệ \\ Phan Tại Huân \\ Email: pthuan@hcmuaf.edu.vn
}

\section{TÓM TẮT}

Trong những năm gần đây, nhiều sản phẩm được sản xuất từ trái mãng cầu ta. Mục tiêu của nghiên cứu này nhằm nâng cao giá trị sử dụng cho loại mãng cầu ta địa phương với sản phẩm nước lên men sử dụng nấm men Saccharomyces cerevisiae. Phương pháp bề mặt đáp ứng được sử dụng nhằm lựa chọn các điều kiện tối ưu về hàm lượng chất rắn hòa tan, tỉ lệ nấm men và thời gian lên men nhằm dể lên men rượu dịch quả mãng cầu ta bằng nấm men Saccharomyces cerevisiae SLS. Thí nghiệm được bố trí theo phương pháp quy hoạch thực nghiệm kiểu thí nghiệm phối hợp có tâm với hàm lượng chất rắn hòa tan trong khoảng từ 16 đến $20^{\circ}$ Brix, tỉ lệ nấm men từ 1 đến $3 \%$, và thời gian lên men từ 42 đến 48 giờ. Sử dụng bề mặt đáp ứng trong mô hình tối ưu bậc 2 dể thể hiện sự ảnh hưởng của các yếu tố khảo sát đến độ cồn và điểm cảm quan. Điều kiện tối ưu để lên men sản phẩm đạt $5,1 \%(\mathrm{v} / \mathrm{v})$ độ cồn được xác định bao gồm hàm lượng chất rắn hòa tan $19^{\circ} \mathrm{Brix}$, tỉ lệ men $2 \%$ và thời gian lên men là 44 giờ. Giá trị mô hình tối ưu dự đoán phù hợp với các giá trị thực nghiệm.

\section{1. Đắt Vấn Đề}

Mãng cầu ta (Annonasquamosa) có nguồn gốc ở vùng nhiệt đới Châu Mỹ. Nhu cầu sử dụng mãng cầu ta rất cao do đây là loại trái cây với phần thịt trái có hương rất thơm, độ axit thấp (Mowry \& ctv., 1941). Trái mãng cầu ta là loại trái cây có đỉnh hô hấp đột biến. Trái chín bình thường ở nhiệt độ $15-30^{0} \mathrm{C}$, nhiệt độ dưới $15^{0} \mathrm{C}$ dễ bị tổn thương lạnh. Điều kiện đề nghị bảo quản trái mãng cầu ở $15-20^{\circ} \mathrm{C}$, nồng độ $\mathrm{O}_{2}$ và ethylen thấp, $10 \% \mathrm{CO}_{2}$ và $85-90 \%$ độ ẩm trong không khí. Hàm lượng axit ascorbic và glucose tăng tối đa tại đỉnh đột biến nhưng lại giảm khi trái quá chín (Broughton \& Guat, 1979). Mặt khác, mãng cầu ta được xem là loại trái ngọt nhất trong họ mãng cầu với thành phần dinh dưỡng khá cao. Tổng lượng carbohydrate 19,6 $\pm 1 \mathrm{~g} / 100 \mathrm{~g}$ trong đó fructose $(3,5 \%)$, glucose $(5,1 \%)$ và oligosaccharides $(1,2-2,5 \%)$. Thịt trái mãng cầu ta là nguồn cung cấp tốt carbohydrate và chất xơ (Hassan \& ctv., 2008). Mãng cầu ta có hàm lượng các chống oxi hóa cao. Hàm lượng phenolic được tìm thấy trong mãng cầu ta có tỉ lệ khá cao $223 \pm 23,8$ mg/100 g (Reddy \& ctv., 2010).

Tây Ninh là tỉnh có vườn mãng cầu ta lớn nhất nước, chủ yếu các xã ven chân núi Bà Đen và các vùng phụ cận. Giống như các loại mãng cầu khác mãng cầu ta dễ bị tổn thương và mềm nhanh chóng trong quá trình chín, trở nên mềm nhão và khó giữ tươi ngon (Raphael \& Omokaro, 2009). Gần đây xuất hiện xu hướng nghiên cứu và phát triển để gia tăng giá trị sử dụng cho nông sản địa phương (Phan \& Nguyen, 2016; Le \& ctv., 2017). Trong nhiều nghiên cứu khoa học, phương pháp bề mặt đáp ứng được áp dụng để tối ưu hóa thông số kỹ thuật với số lượng nghiệm thức vừa phải (Ngo \& ctv., 2016; Živković \& ctv., 2018). Nhằm nâng cao giá trị sử dụng, góp phần đa dạng hóa sản phẩm, nghiên cứu này thực hiện với mục tiêu làm tiền đề chế biến sản phẩm nước trái cây lên men từ trái mãng cầu ta. Mục tiêu của nghiên cứu là tối ưu hóa quá trình lên men rượu dịch quả mãng cầu ta bằng cách sử dụng nấm men 
Saccharomyces cerevisiae SLS.

\section{Vật Liệu và Phương Pháp Nghiên Cứu}

Nguyên liệu: Trái mãng cầu ta có nguồn từ núi Bà Đen, tỉnh Tây Ninh.

Chủng vi sinh vật: Nấm men Saccharomyces cerevisiae SLS do Viện Vi Sinh Vật và Công Nghệ Sinh Học, Đại học quốc gia Hà Nội cung cấp.

Hóa chất: Môi trường Potato Dextrose Broth (PDB) để trữ giống nấm men với thành phần gồm $200 \mathrm{~g}$ khoai tây, $20 \mathrm{~g}$ đường glucose và 1000 $\mathrm{mL}$ nước cất. Trong đó, khoai tây rửa sạch cắt hình khối $1 \mathrm{~cm}$, cho nước vừa đủ vào đun sôi 15 - 20 phút, gạn lấy dịch trong (nước chiết khoai tây) thêm nước vừa đủ $1000 \mathrm{~mL}$, cho vào đường, khuấy đều và đun lửa nhỏ cho tan hết, cho vào bình khử trùng bằng autoclave ở $121^{\circ} \mathrm{C}$ trong 15 phút.

Chuẩn bị mẫu: Quy trình lên men nước mãng cầu ta được thể hiện như Hình 1.

Cách tiến hành: Mãng cầu ta được lột vỏ, tách hạt và cuống; bổ sung nước với tỷ lệ $1: 2,5(\mathrm{w} / \mathrm{v})$, bổ sung $\mathrm{Na}_{2} \mathrm{~S}_{2} \mathrm{O}_{5}$ với hàm lượng là $0,1 \%$ thịt quả (Okeke \& ctv., 2015); xay nhuyễn, lọc lấy dịch, thêm đường đến độ Brix khảo sát; bổ sung tỷ lệ Saccharomyces cerevisiae SLS (\% nấm men, v/v) khảo sát với mật độ $10^{7}$ tế bào $/ \mathrm{mL}$; lên men chính ở điều kiện kị khí, nhiệt độ phòng.

Tối ưu quá trình lên men: Xử lý số liệu thí nghiệm theo phương pháp quy hoạch thực nghiệm kiểu thí nghiệm phối hợp có tâm (CCD), được bố trí bằng phần mềm JMP 10. Mối quan hệ giữa yếu tố khảo sát và chỉ tiêu theo dõi thể hiện dưới dạng bề mặt đáp ứng. Các yếu tố trong thí nghiệm là độ Brix $\left(\mathrm{X}_{1}\right), \%$ nấm men $\left(\mathrm{X}_{2}\right)$, thời gian lên men $\left(\mathrm{X}_{3}\right)$ theo các mức thể hiện ở Bảng 1 .

Trên cơ sở xác định $\mathrm{X}_{1}, \mathrm{X}_{2}, \mathrm{X}_{3}$ phương trình hồi quy được xây dựng để xác định ảnh hưởng của 3 yếu tố đến chỉ tiêu theo dôi là độ cồn $\mathrm{Y}_{1}$ $(\% \mathrm{v} / \mathrm{v})$ và điểm cảm quan $\left(\mathrm{Y}_{2}\right)$. Phương trình hồi quy có dạng tổng quát:

$$
\begin{gathered}
\mathrm{Y}=\mathrm{a}_{0}+\mathrm{a}_{1} \mathrm{x}_{1}+\mathrm{a}_{2} \mathrm{x}_{2}+\mathrm{a}_{3} \mathrm{x}_{3}+\mathrm{a}_{12} \mathrm{x}_{1} \mathrm{x}_{2}+ \\
\mathrm{a}_{13} \mathrm{x}_{1} \mathrm{x}_{3}+\mathrm{a}_{23} \mathrm{x}_{2} \mathrm{x}_{3}+\mathrm{a}_{11} \mathrm{x}_{0}^{2}+\mathrm{a}_{22} \mathrm{x}_{0}^{2}+\mathrm{a}_{33} \mathrm{x}_{3}^{2}
\end{gathered}
$$

Được tối ưu hóa theo hướng điểm cảm quan sản phẩm đạt giá trị tối đa trong khi độ cồn sản phẩm nằm trong khoảng độ cồn phổ biến của nước trái cây lên men là $4,5-5,5 \%(\mathrm{v} / \mathrm{v})$.

Các phương pháp phân tích hóa lý:

Hàm lượng chất rắn hòa tan (độ Brix) được đo bằng khúc xạ kế Atago $0-32^{0} \operatorname{Brix}\left( \pm 0,1^{0}\right.$ Brix $)$.

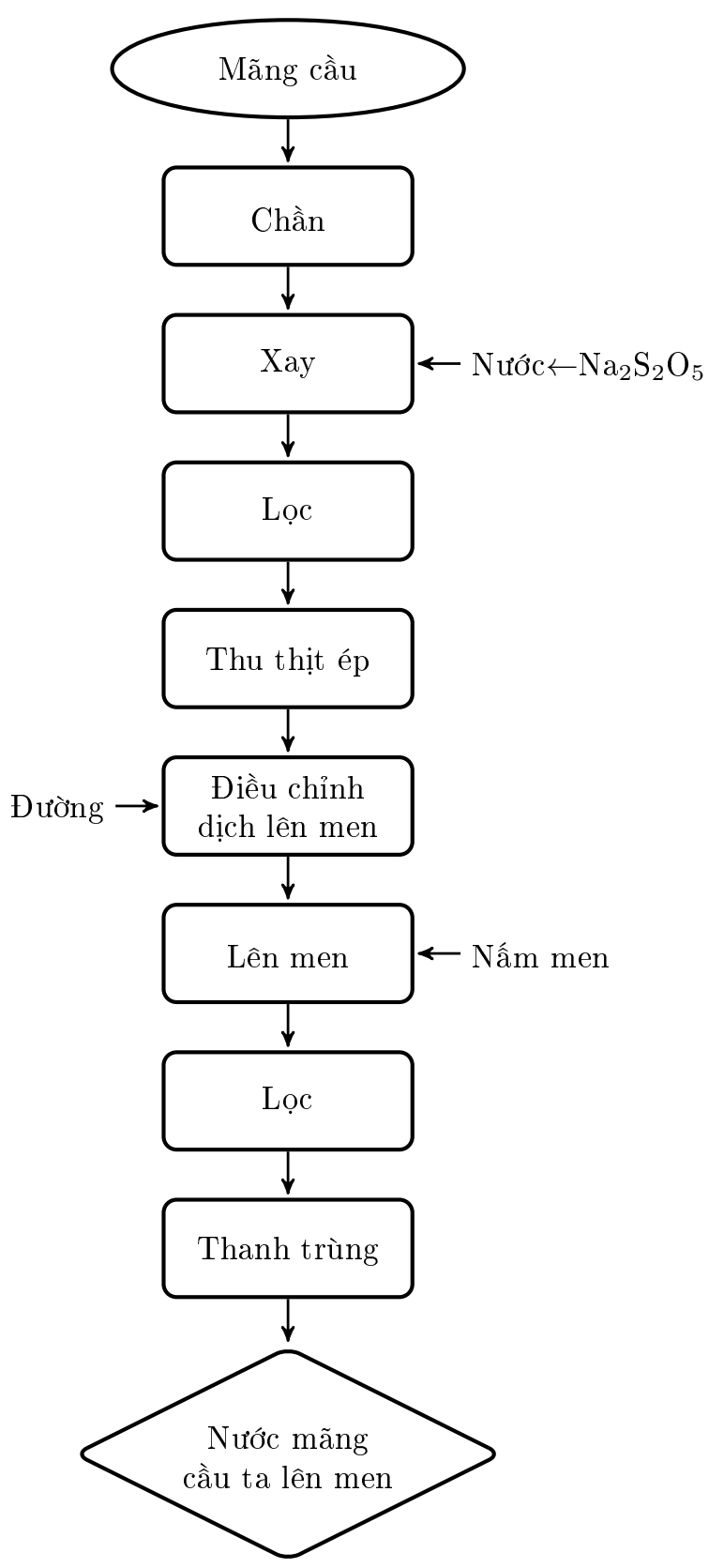

Hình 1. Quy trình lên men nước mãng cầu ta. 
Bảng 1. Bố trí thí nghiệm tối ưu hóa quá trình lên men

\begin{tabular}{lccc}
\hline \multirow{2}{*}{ Biến (yếu tố) } & \multicolumn{3}{c}{ Mức và mã hóa mức của biến } \\
\cline { 2 - 4 } & -1 & 0 & +1 \\
\hline $\mathrm{X}_{1}$ : Độ Brix & 16 & 18 & 20 \\
$\mathrm{X}_{2}$ : \% Nấm men & 1 & 2 & 3 \\
$\mathrm{X}_{3}$ : Thời gian lên men (giờ) & 42 & 45 & 48 \\
\hline
\end{tabular}

Bảng 2. Một số chỉ tiêu hóa lý của thịt quả mãng cầu ta xay nhuyễn

\begin{tabular}{lc}
\hline Chì tiêu & Kết quả $(\mathrm{X} \pm \mathrm{SD})^{1}$ \\
\hline Hàm lượng chất rắn hòa tan & $21,2 \pm 0,12$ \\
$\mathrm{pH}$ & $5,13 \pm 0,01$ \\
Vitamin C & $45,86 \pm 0,02 \mathrm{mg} / 100 \mathrm{~mL}$ \\
Polyphenol & $33,26 \pm 0,03 \mathrm{mg} / 100 \mathrm{~mL}$ \\
\hline${ }^{1} \mathrm{X} \pm$ SD: Giá trị trung bình \pm độ lệch chuẩn
\end{tabular}

pH của mẫu được đo bằng máy đo pH (Hanna pH211 - USA).

Hàm lượng ethanol được xác định theo TCVN 6429: 2007.

Hàm lượng polyphenol tổng được xác định bằng phương pháp Folin - Ciocalteu theo ISO 14502-1: 2005.

Hàm lượng vitamin $\mathrm{C}$ được xác định bằng phương pháp quang phổ UV - Vis (Kapur \& ctv., 2012).

Phương pháp cảm quan: Đánh giá chất lượng sản phẩm bằng phương pháp cảm quan cho điểm dựa theo TCVN 3217-79 (Rượu - Cảm quan Phương pháp cho điểm). Thí nghiệm được bố trí theo kiểu bố trí khối không đầy đủ cân đối (Balanced incomplete block). Mẫu được đánh giá cảm quan theo phương pháp cho điểm với thang điểm 20. Hội đồng cảm quan viên gồm các thành viên có khả năng đánh giá khách quan, có khả năng phân biệt cảm giác tốt, có kiến thức chuyên môn và kiến thức phân tích cảm quan. Cảm quan viên đánh giá 4 mẫu trong 15 mẫu thí nghiệm. Mỗi mẫu được đánh giá với số lần đánh giá như nhau. Khối mẫu cũng được bố trí ngẫu nhiên cho mỗi cảm quan viên. Thứ tự trình bày mẫu trong khối phải ngẫu nhiên trong tất cả các trường hợp.

\section{Kết Quả và Thảo Luận}

\subsection{Khảo sát chất lượng nguyên liệu mãng cầu ta}

Do đặc tính của nguyên liệu là một trong những chỉ tiêu rất quan trọng quyết định trực tiếp đến chất lượng sản phẩm cũng như khả năng phát triển, lên men của nấm men và giá trị cảm quan của sản phẩm. Đây là điều kiện cần thiết giúp ta có thể điều chỉnh các thông số và phối chế dịch lên men để tạo ra một sản phẩm có chất lượng về mặt dinh dưỡng cũng như cảm quan. Kết quả xác định một số chỉ tiêu trong nguyên liệu được trình bày ở Bảng 2.

Kết quả cho thấy trái mãng cầu ta có lượng đường tương đối cao với hàm lượng chất rắn hòa tan vào khoảng $21,2^{0}$ Brix. Vitamin $\mathrm{C}$ của mãng cầu ta vào khoảng $45,86 \mathrm{mg} / 100 \mathrm{~mL}$ gần bằng với dứa $(51 \mathrm{mg} / 100 \mathrm{~mL})$ và thấp hơn so với ổi $(130$ $300 \mathrm{mg} / 100 \mathrm{~mL}$ ) (Quach \& ctv., 2008). Tuy nhiên đó là hai loại trái cây giàu vitamin $\mathrm{C}$ nên cũng vẫn có thể kết luận được rằng mãng cầu ta là trái cây có lượng vitamin tương đối cao. Chính vì vậy việc chế biến và đa dạng hóa các sản phẩm từ loại quả này là rất tốt cho sức khỏe người tiêu dùng.

Khi lên men ethanol, $\mathrm{pH}$ của dịch quả cũng là yếu tố cần được chú ý. Trái mãng cầu ta được nghiên cứu có $\mathrm{pH} 5,3$ nằm ở khoảng $\mathrm{pH} 4,5$ - 5,5, thích hợp để nấm men phát triển (Luong, 2009). Đó cũng chính là lý do trong nghiên cứu này sẽ không điều chỉnh pH khi lên men nước mãng cầu ta.

Bên cạnh đó polyphenol là các hợp chất có vai trò quan trọng trong các quá trình trao đổi chất (điều khiển trao đổi năng lượng và tái tạo protein) của rau quả. Hợp chất polyphenol dễ bị oxy hóa tạo thành flobafen có màu nâu hay đỏ với tốc độ rất nhanh và là nguyên nhân chính gây sẫm màu các quả khi chế biến. Trong mãng cầu ta có lượng polyphenol tương đối cao $(33,26 \mathrm{mg} / 100 \mathrm{~mL})$. Do đó khi chế biến cần có những biện pháp xử lý để tránh làm sẫm màu sản phẩm. 


\section{2. Ảnh hưởng của các yếu tố khảo sát đến} độ cồn sản phẩm

Với sản phẩm nước trái cây lên men thì độ Brix, tỷ lệ men và thời gian lên men là các yếu tố có tầm ảnh hưởng quyết định tới chất lượng sản phẩm. Kết quả tối ưu quá trình lên men khảo sát các yếu tố độ Brix 16 - 20, tỉ lệ nấm men $1-3 \%$ và thời gian lên men 42 - 48 giờ được thể hiện ở Bảng 3.

\section{Actual by Predicted Plot}

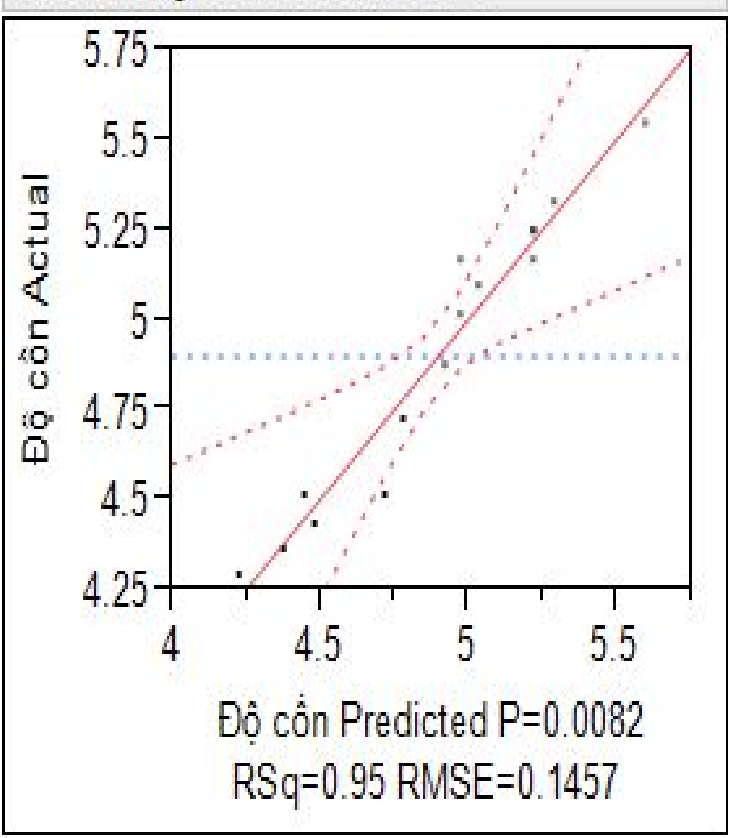

Hình 2. Sự tương quan giữa độ cồn thực tế và dự đoán.

Hệ số tương thích của độ cồn $\left(\mathrm{R}^{2}=0,95\right)$ được thể hiện trong Hình 2. Điều đó có nghĩa là mô hình được lựa chọn cho bố trí thí nghiệm là phù hợp và tương thích với các số liệu thí nghiệm. Giá trị $P=0,0082(P<0,05)$ cho thâyy các yếu tố khảo sát như độ Brix, $\%$ nấm men và thời gian lên men ảnh hưởng có ý nghĩa đến sự biến thiên độ cồn.

Phương trình hồi quy với ba yếu tố của hàm mục tiêu (độ cồn) theo mô hình tôi ưu đã chọn có dạng như phương trình: $\mathrm{Y}_{1}=4,97+0,4 \mathrm{X}_{1}+$ $0,15 \mathrm{X}_{2}+0,13 \mathrm{X}_{3}$.

Trong đó:

Các hệ số tương ứng được chọn khi có ảnh hưởng ý nghĩa về mặt thống kê đến chỉ tiêu theo dõi $(P<0,05)$. Ba yếu tố độ Brix, nồng độ nấm men và thời gian lên men đều ảnh hưởng mạnh mẽ đến độ cồn tổng thu được.

$\mathrm{Y}_{1}$ là độ cồn $(\%) ; \mathrm{X}_{1}$ độ $\mathrm{Brix}, \mathrm{X}_{2}$ tỉ lệ nấm men $(\%), \mathrm{X}_{3}$ thời gian lên men (giờ). Dấu đứng trước các hệ số, cho biết chiều ảnh hưởng của các yếu tố là dương hay âm, nói cách khác là độ biến thiên của các yếu tố tỉ lệ nghịch hay thuận đối với độ biến thiên của chỉ tiêu theo dõi. Từ phương trình, ta thấy được, cả ba yếu tố đều tương quan tỉ lệ thuận với độ cồn. Mức độ ảnh hưởng của các yếu tố thể hiện qua biểu đồ Pareto (Hình 3).

Kết quả cho thấy độ Brix có mức ảnh hưởng đến sự biến thiên độ cồn nhất. Điều này cho thấy độ Brix là yếu tố quan trọng nhất ảnh hưởng đến độ cồn sau khi lên men, theo đó đến tî̉ lệ nấm men và thời gian lên men là yếu tố có ảnh hưởng yếu hơn. Ngoài ra, chiều hướng tác động của từng yếu tố khảo sát được biểu diễn chi tiết tại Hình 4.

Ba yếu tố đều ảnh hưởng đến độ cồn theo đường gần như thẳng. Điều này đã được biết đến qua phương trình hồi quy, các yếu tố khảo sát đều ảnh hưởng ở hàm bậc một. Trong phạm vi khảo sát hạn chế, khi tăng giá trị của yếu tố tới một giới hạn nhất định thì độ cồn tăng dần đến giá trị cực đại. Nghiên cứu của Yan \& ctv. (2012) cũng cho thấy nồng độ đường càng lớn sẽ càng làm giảm quá trình chuyển hóa rượu. Đường có trong dịch lên men đóng vai trò là nguồn cacbon phục vụ cho quá trình sinh trưởng và lên men của nấm men. Tuy nhiên, nếu hàm lượng đường quá cao sẽ ức chế hoạt động sống của nấm men do tăng áp suất thẩm thấu giữa tế bào với môi trường (Attri, 2009). Trong khi đó theo Bui (2009) thời gian lên men tác động lớn đến quá trình lên men nước trái cây. Nếu kéo dài thời gian lên men sẽ dẫn đến hàm lượng cồn tăng cao. Khi đó sản phẩm không còn là nước trái cây lên men mà là rượu trái cây. Nên việc canh chỉnh thời gian trong nước trái cây lên men là một trong các yếu tố quan trọng quyết định hàm lượng cồn sinh ra nhiều hay ít.

\section{3. Ảnh hưởng của các yếu tố khảo sát đến điểm cảm quan sản phẩm}

Bên cạnh khảo sát đáp ứng độ cồn, thí nghiệm còn khảo sát thêm đáp ứng điểm cảm quan. Kết quả xử lý cho thấy hệ số tương thích của điểm cảm quan $\left(\mathrm{R}^{2}=0,93\right)$ được thể hiện như Hình 5 Điều đó cũng có nghĩa là mô hình được chọn cho bố trí thí nghiệm là phù hợp. Giá trị $P=0,019$ 
Bảng 3. Kết quả tối ưu quá trình lên men bố trí theo kiểu CCD

\begin{tabular}{cccccc}
\hline NT & Độ Brix $\%$ & Nấm men & Thời gian (giờ) & Độ cồn $(\%, \mathrm{v} / \mathrm{v})$ & Điểm cảm quan \\
\hline 1 & 16 & 1 & 42 & 4,29 & 15,6 \\
2 & 20 & 1 & 42 & 5,09 & 17,0 \\
3 & 16 & 3 & 42 & 4,51 & 15,0 \\
4 & 16 & 1 & 48 & 4,36 & 17,4 \\
5 & 20 & 3 & 42 & 5,24 & 17,2 \\
6 & 20 & 1 & 48 & 5,16 & 17,2 \\
7 & 16 & 3 & 48 & 4,72 & 16,8 \\
8 & 20 & 3 & 48 & 5,54 & 17,4 \\
9 & 18 & 2 & 45 & 5,01 & 16,4 \\
10 & 18 & 2 & 42 & 4,51 & 16,2 \\
11 & 18 & 2 & 48 & 5,16 & 17,6 \\
12 & 18 & 1 & 45 & 4,87 & 16,6 \\
13 & 18 & 3 & 45 & 5,24 & 17,2 \\
14 & 16 & 2 & 45 & 4,43 & 14,8 \\
15 & 20 & 2 & 45 & 5,32 & 16,8 \\
\hline
\end{tabular}

Bảng 4. Độ cồn và điểm cảm quan theo dự đoán của mô hình tối ưu và thực tế

\begin{tabular}{lccccc}
\hline & \multicolumn{3}{c}{ Yếu tố khảo sát } & \multirow{2}{*}{ Độ cồn $(\%)$} & \multirow{2}{*}{ Cảm quan } \\
\cline { 2 - 4 } & Độ Brix & $\%$ nấm men & Thời gian (giờ) & & \\
\hline Giá trị dự đoán & 19,16 & 1,90 & 43,96 & 5,10 & 16,51 \\
Giá trị hiệu chỉnh & 19,00 & 2,00 & 44,00 & 5,09 & 16,51 \\
Thực nghiệm kiểm chứng & 19,00 & 2,00 & 44,00 & 5,10 & 16,47 \\
\hline
\end{tabular}

\section{Pareto Plot of Transformed Estimates}

Term

Độ brix $(16,20)$

$\%$ nấm men( 1,3$)$

Thời gian $(42,48)$

Thời gian ${ }^{\star}$ Thời gian

Độ brix*Độ brix

$\%$ nấm men*Thời gian

$\%$ nấm men $*$ nấm men

Độ brix ${ }^{*}$ Thời gian

Độ brix \% nầm men
Orthog

Estimate

0.3298646

0.1208415

0.1061446

$-0.0506048$

$-0.0433692$

0.0337762

0.0271574

0.0082158

$-0.0045644$

Hình 3. Mức độ ảnh hưởng của 3 yếu tố khảo sát đến chỉ tiêu độ cồn.

$(P<0,05)$ cho thấy các yếu tố khảo sát như độ Brix, \% nấm men Saccharomyces cerevisiae SLS và thời gian có ảnh hưởng ý nghĩa đến sự biến thiên về điểm cảm quan.
Phương trình hồi quy bậc hai với ba yếu tố của hàm mục tiêu điểm cảm quan theo mô hình tối ưu đã chọn có dạng như phương trình:

$$
\mathrm{Y}_{2}=16,44+0,6 \mathrm{X}_{1}+0,54 \mathrm{X}_{3}-0,64 \mathrm{X}_{1}^{2}-
$$




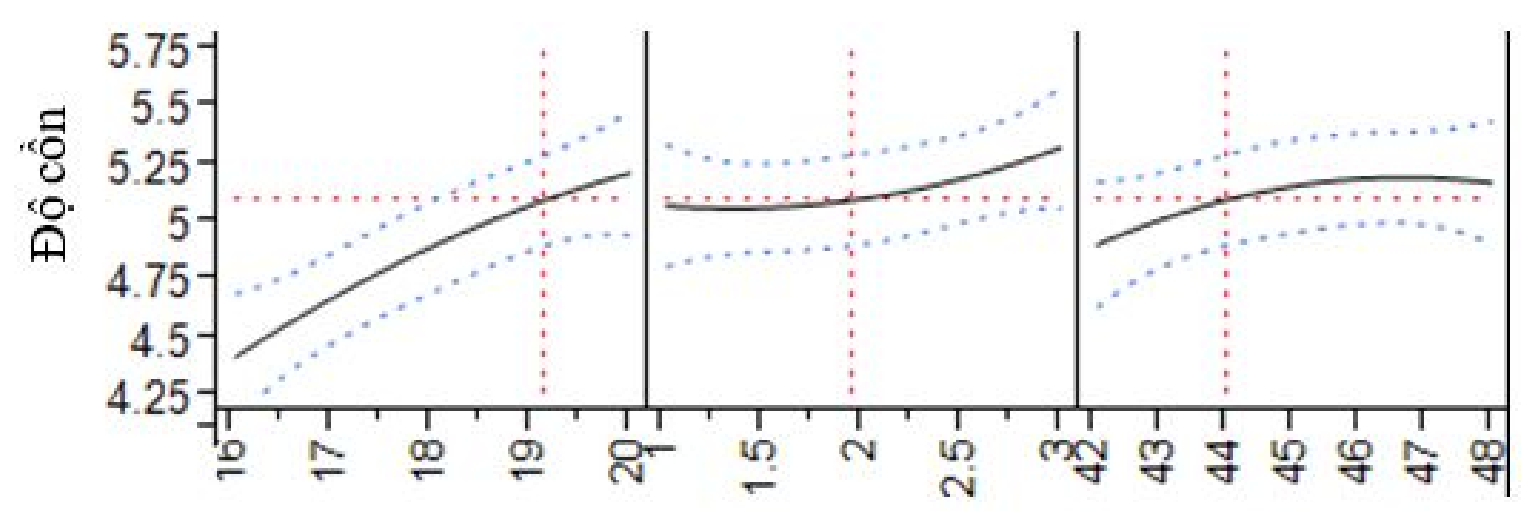

Hình 4. Chiều hướng tác động của 3 yếu tố khảo sát đến chỉ tiêu độ cồn.

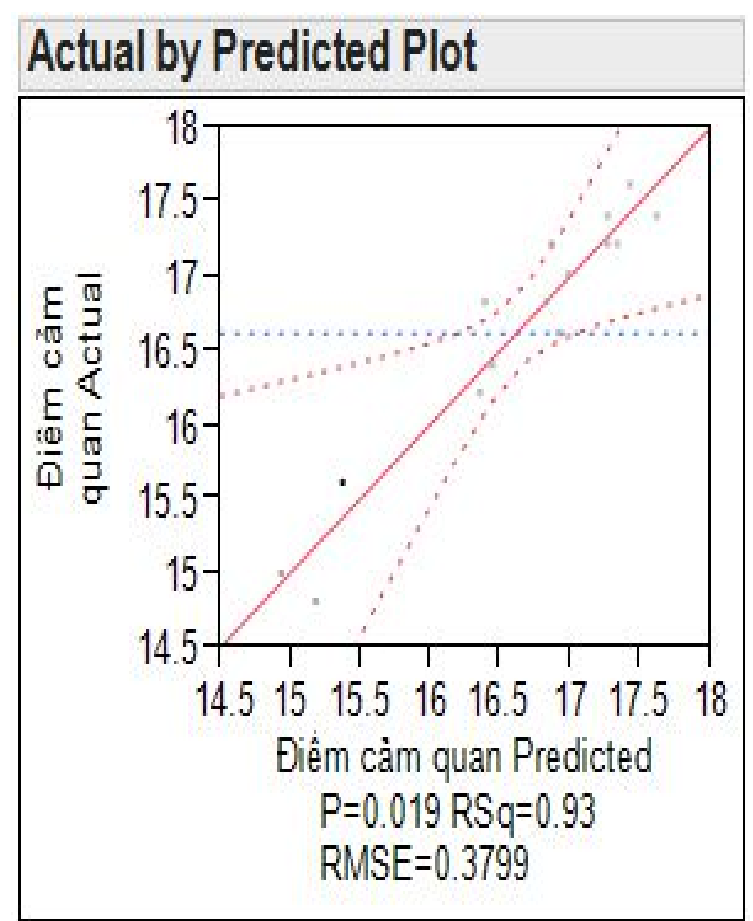

Hình 5. Sự tương quan giữa điểm cảm quan thực tế và dự đoán.

\section{$0,4 \mathrm{X}_{1} \mathrm{X}_{3}$}

Trong đó: $\mathrm{Y}_{2}$ là điểm trung bình cảm quan; $\mathrm{X} 1$ độ brix, $\mathrm{X}_{2}$ tỉ lệ nấm men $(\%), \mathrm{X}_{3}$ thời gian lên men (giờ).

Phân tích Pareto cho thấy yếu tố độ Brix ảnh hưởng nhiều nhất đến điểm quan, tiếp đó là thời gian lên men (Hình 6). Điều này có thể giải thích độ Brix ảnh hưởng nhiều đến vị của sản phẩm. Yếu tố \% nấm men được cho là không ảnh hưởng đáng kể đến điểm cảm quan.
Chiều hướng tác động của ba yếu tố khảo sát đến điểm cảm quan được thể hiện trong Hình 7. Các ảnh hưởng này đều thể hiện theo đường cong, tương thích với phương trình hồi quy bậc hai. Trong khoảng khảo sát, điểm cảm quan tăng dần theo độ Brix tuy nhiên sẽ giảm nếu độ Brix nằm trong khoảng hơn 19,5. Điểm cảm quan cũng tăng dần theo thời gian khảo sát. Yếu tố \% nấm men không có ảnh hưởng đáng kể đến điểm cảm quan.

\subsection{Tối ưu hóa quá trình lên men}

Kết quả tối ưu hóa theo giá trị điểm cảm quan đạt được với hàm lượng chất rắn hoà tan $19,1^{0}$ Brix; tỉ lệ nấm men $1,9 \%$; thời gian lên men 44 giờ. Giá trị điểm cảm quan cực đại đạt được là 16,5. Tại giá trị cực đại này, độ cồn dự đoán là $5,1 \%(\mathrm{v} / \mathrm{v})$ phù hợp hoàn toàn với khoảng cho phép 4,5 - 5,5\% (v/v) đối với nước trái cây lên men. Do đó kết quả này được lựa chọn làm giá trị tối ưu cho quá trình lên men nước mãng cầu ta. Kết quả này cũng khá tương thích với kết quả của nhiều nghiên cứu khác như lên men rượu vang điều (Attri, 2009), rượu vang ổi (Sevda \& Rodrigues, 2010), và lên men rượu vang từ xơ mít (Nguyen, 2010).

Từ kết quả dự đoán của mô hình, thực hiện kiểm chứng thực tế với các số liệu được hiệu chỉnh làm tròn cho phù hợp được thể hiện như trong Bảng 4. Kết quả giá trị thực tế cho thấy phù hợp với dự đoán là $5,1 \%(\mathrm{v} / \mathrm{v})$. Điểm cảm quan cho giá trị thực tế là 16,47 , đạt loại khá. So với giá trị dự đoán, cả hai đáp ứng độ cồn và điểm cảm quan đều cho kết quả sai khác không có ý nghĩa $(P<0,05)$. 


\section{Pareto Plot of Transformed Estimates}

\section{Term}

Độ brix $(16,20)$

Thời gian $(42,48)$

Độ brix*Thời gian

$\%$ nấm men $\%$ nấm men

Thời gian*Thời gian

Độ brix $\%$ nẩm men

Độ brix*Độ brix

$\%$ nấm men(1,3)

$\%$ nấm men ${ }^{*}$ Thời gian
Orthog

Estimate

0.4898979

0.4409082

$-0.2921187$

0.2530575

0.1886179

0.1460593

$-0.1319933$

$-0.0163299$

$1.6216 \mathrm{e}-16$

Hình 6. Mức độ ảnh hưởng của 3 yếu tố khảo sát đến chỉ tiêu điểm cảm quan.

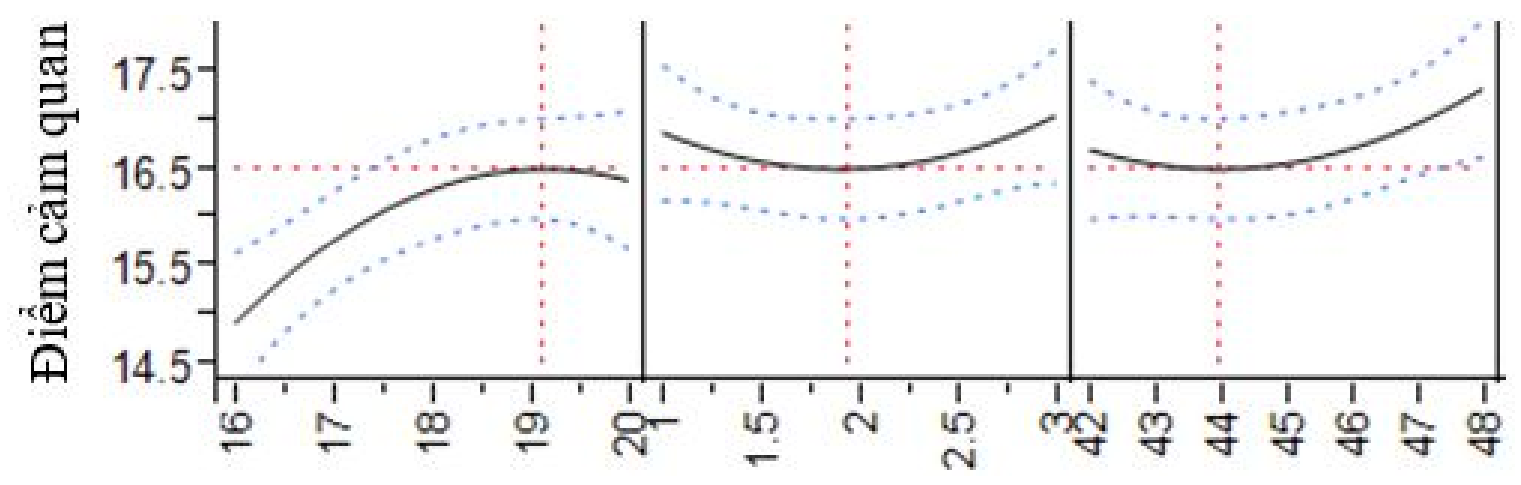

Hình 7. Chiều hướng tác động của 3 yếu tố khảo sát đến điểm cảm quan.

\section{Kết Luận}

Trái mãng cầu ta với giá trị trung bình hàm lượng chất rắn hoà tan $21,2^{0} \mathrm{Brix}, \mathrm{pH} 5,13$, Vitamin $\mathrm{C} 45,86 \mathrm{mg} / 100 \mathrm{~mL}$ và polyphenol 33,26 $\mathrm{mg} / 100 \mathrm{~mL}$ có thể được sử dụng dịch quả để lên men bằng nấm men Saccharomyces cerevisiae $S L S$. Bằng phương pháp quy hoạch thực nghiệm sử dụng bề mặt đáp ứng trong mô hình tối ưu bậc 2, điều kiện tối ưu cho 3 thông số kỹ thuật chính của quá trình lên men được xác định. Vởi giá trị tối ưu hàm lượng chất rắn hòa tan của dịch lên men là $19^{0} \mathrm{Brix}$, tỷ lệ nấm men sử dụng $2 \%$ và thời gian lên men 44 giờ cho sản phẩm lên men đạt giá trị tốt nhất. Giá trị đạt được dự đoán theo mô hình tối ưu không có sự khác biệt đáng kể so với giá trị thực nghiệm. Sản phẩm thu được có độ cồn $5,1 \%(\mathrm{v} / \mathrm{v})$ nằm trong vùng phổ biến của nước trái cây lên men và có điểm cảm quan là 16,47 , đạt loại khá theo TCVN.

\section{Lời Cảm Ơn}

Nghiên cứu được tài trợ bởi Sở Khoa Học Và Công Nghệ Tây Ninh.

\section{Tài Liệu Tham Khảo (References)}

Attri, B. L. (2009). Effect of initial sugar concentration on the physico-chemical characteristics and sensory qualities of cashew apple wine. Natural Product Radiance 
8(4), 374-379.

Broughton, W. J., \& Guat, T. (1979). Storage conditions and ripening of the custard apple Annona squamosa L. Scientia Horticulturae 10(1), 73-82.

Bui, A. (2009). Fermentation technology applied in food technology. Ho Chi Minh City, Vietnam: VNU Ho Chi Minh Publishing House.

Hassan, L. G., Muhammad, M. U., Umar, K. J., \& Sokoto, A. M. (2008). Comparative Study on the proximate and mineral contents of the seed and pulp of sugar apple (Annona squamosa). Nigerian Journal of Basic and Applied Sciences 16(2), 179-182.

Phan, H. T., \& Nguyen, H. T. M. (2016). Polyphenol content and antioxidant capacity of herbal tea from Vietnamese water hyssop (Bacopa monnieri). International Journal on Advanced Science, Engineering and Information Technology 6(1), 61-68.

Kapur, A., Haskovic, A., Copra-Janicijevic, A., Klepo, L., Topcagic, A., Tahirovic, I., \& Sofic, E. (2012). Spectrophotometric analysis of total ascorbic acid contetnt in various fruits and vegetables. Bulletin of the Chemists and Technologists of Bosnia and Herzegovina 38 (4), 39-42.

Le, T. T., Phan, T. H., \& Raes, K. (2017). Establishment of a processing procedure for manufacturing dried dragon fruit. Journal of Agricultural Sciences and Technology 6, 32-38.

Luong, P. D. (2009). Industrial Yeasts. Ha Noi, Vietnam: Science and Technics Publishing House.

Mowry, H., Toy, L. R., \& Wolfe, H. S. (1941). Miscellaneous tropical and subtropical florida fruits. Bulletin - University of Florida Agricultural Extension Service 109, 11-21.

Ngo, N. T. T., Phan, H. T., \& Nguyen, T. T. B. (2016). Screening of fungal strains grown in solid-state culture for production of pectinase from coffee husk. International Journal on Advanced Science, Engineering and Information Technology 6(3), 273-276.
Nguyen, S. T. T. (2010). Experimental fermentation of wine from ripe jackfruit. Journal of Sciences and Application 12, 28-29.

Okeke, B. C., Agu, K. C., Uba, P. O., Awah, N. S., Anaukwu, C. G., Archibong, E. J., Uwanta, L. I., Ezeneche, J. N., Ezenwa, C. U., \& Orji, M. U. (2015). Wine Production from Mixed Fruits (Pineapple and Watermelon) Using High Alcohol Tolerant Yeast Isolated from Palm Wine. Universal Journal of Microbiology Research 3(4), 41-45.

Quach, D., Nguyen, T. V., \& Nguyen, T. V. (2008). Fruits and vegetables preservation and processing. Ha Noi, Vietnam: Science and Technics Publishing House.

Raphael, N. O., \& Omokaro, O. (2009). Mycoflora and production of wine from fruits of soursop (Annona muricata L.). International Journal of Wine Research $1,1-9$.

Reddy, C., Vijaya, K., Sreeramulu, D., \& Raghunath, M. (2010). Antioxidant activity of fresh and dry fruits commonly consumed in India. Food Research International 43(1), 285-288.

Sevda, S. B., \& Rodrigues, L. (2011). Fermentative behavior of Saccharomyces strains during Guava (Psidium guajava L.) must fermentation and optimization of guava wine production. Journal of Food Processing and Technology 2 (4), 1-18.

Yan, L., Wei, Z., Chunjie, L., Kei, S., Shuzo, T., \& Hainan K. (2012). Factors affecting ethanol fermentation using Saccharomyces cerevisiae BY4742. Biomass and Bioenergy 47, 395-401.

Živković, J., S̆avikin, K., Janković, T., Ćujić, N., \& Menković, N. (2018). Optimization of ultrasoundassisted extraction of polyphenolic compounds from pomegranate peel using response surface methodology. Separation and Purification Technology 194, 40-47. 